\title{
Extreme rainfall in Cumbria, November 2009 - an assessment of storm rarity
}

\author{
Lisa Stewart ${ }^{1}$, Dave Morris ${ }^{1}$, David Jones ${ }^{1}$ and Peter Spencer ${ }^{2}$ \\ ${ }^{1}$ Centre for Ecology and Hydrology, Wallingford, UK; ${ }^{2}$ Environment Agency, North West Region, UK \\ Email: ejs@ceh.ac.u,
}

\begin{abstract}
A new UK record was established at Seathwaite Farm, Borrowdale, recently, when $316.4 \mathrm{~mm}$ of rainfall was recorded over the 24-hour period up to 00:00 on 20 $20^{\text {th }}$ November 2009. This exceptional event followed several days of heavy rainfall, and caused widespread flooding in Cumbria, which particularly affected the communities of Cockermouth and Workington and extended into southwest Scotland. Drawing on the results of a recent project which has developed a new model of point rainfall depth-duration-frequency (DDF) for the UK, return periods are estimated for rainfall observations available for the Cumbrian event at two raingauge sites. The new model has been designed as a replacement for the Flood Estimation Handbook (FEH) rainfall model and has been specifically developed to apply to very extreme events. The paper demonstrates how valuable even relatively short raingauge records can be in upland areas such as the Lake District in improving estimates of storm frequency.
\end{abstract}

\section{Introduction}

Widespread floods were experienced in Northern Ireland, north Wales, north-west England and Scotland in November 2009 following a prolonged period of wet weather that included a new 24-hour rainfall maximum for a UK raingauge. The most serious effects occurred in west Cumbria from the $19^{\text {th }}$ November onwards, with the towns of Cockermouth and Workington experiencing particularly severe flooding which inundated large numbers of properties and caused transport chaos. A police officer died in Workington after a road bridge collapsed. This paper considers the statistical frequency of some of the highest raingauge observations from the event in Cumbria, comparing return periods from a new model of rainfall depth-durationfrequency with results from the Flood Estimation Handbook (FEH) rainfall model (Faulkner, 1999).

\section{Details of the rainfall event in November 2009}

A warm, moist south-westerly airstream affected the UK between the $18^{\text {th }}$ and $20^{\text {th }}$ November 2009 which was associated with a very deep Atlantic depression tracking slowly north-eastwards between Scotland and Iceland (Met Office, 2009). A weather front within this airstream, together with substantial orographic enhancement, produced many storm totals of greater than $50 \mathrm{~mm}$ and culminated in extreme rainfall depths across high ground in the Lake District. The highest observation was at Seathwaite Farm in Borrowdale, with $316.4 \mathrm{~mm}$ of rainfall recorded over a 24-hour period. This exceeded the previous record of $279 \mathrm{~mm}$, which was the recognised 24-hour maximum rainfall, and remains the rainfall-day maximum, during the Martinstown storm of July 1955. It should be noted that the Seathwaite Farm 24-hour total exceeds the UK maximum for any two consecutive rainfall days (315 mm, also at Seathwaite Farm, on 4-5 December 1864) (Eden and Burt, 2010).

\section{Assessing the frequency of extreme rainfalls}

The UK is fortunate in having long records of raingauge observations going back, in many cases, to the 1860 s when George Symons started to develop a network of rainfall monitors that became the British Rainfall Organization (Pedgley, 2010). Although many of the early records still remain to be digitised, the UK has a long history of rainfall depth-duration-frequency (DDF) modelling for the assessment of water resources, hydrological design and postevent analysis. Volume II of the Flood Studies Report (NERC, 1975) presented a model of UK rainfall frequency that has had a worldwide influence, but was criticised for being overgeneralised (Faulkner, 1999). The Flood Studies Report (FSR) was superseded by the Flood Estimation Handbook (FEH) (Institute of Hydrology, 1999), which introduced a new set of procedures for the estimation of rainfall and flood frequency in the UK, based on digital catchment information and the use of flexible regionalisation schemes.

Recent research under the Joint Environment Agency/Defra Flood and Coastal Risk Management R\&D Programme has developed a new model of rainfall depthduration frequency (DDF) applicable to the whole of the UK (Stewart et al., 2010). The project was led by CEH and involved researchers from the Met Office and the Universities of Salford and Sheffield. The new model has been developed for rainfall durations from 1 hour to 8 days, and was commissioned in response to concerns expressed by reservoir engineers about the apparently high rainfall depth estimates produced by the FEH rainfall model when it was applied to return periods in excess of its recommended upper limit of 1000 years. One particular aspect of the FEH model that was considered to be in need of revisiting was the form of the extrapolation used to provide rainfall inputs to reservoir flood safety assessments (MacDonald and Scott, 2001).

The new DDF model has been designed to provide rainfall estimates for return periods ranging from 2 to over 10000 years, and it is proposed that it should eventually replace the FEH rainfall model for hydrological design and 
analysis in the UK. The project team was able to extend the dataset of annual maximum rainfall depths used in the FEH analysis in terms of both record length and the density of raingauge sites, particularly for sub-daily durations, where the number of raingauges with suitable records was increased from 375 to 969 . The basic approach mirrored that used in the FEH rainfall analysis, which adopted a two-stage index-flood methodology, and a number of key revisions were introduced. Firstly, the simple standardisation used in the FEH, whereby annual maxima at each raingauge are divided by the at-site median value of the appropriate duration (RMED), was replaced by a revised standardisation designed to remove more of the location-dependent variation in the distribution of rainfall before combining data from networks of raingauges. The second stage used in the FEH was the application of the Focused Rainfall Growth Extension (FORGEX) methodology (Faulkner, 1999). The project has made a number of changes to FORGEX, most notably by using a new model of the spatial dependence in rainfall extremes that allows dependence to reduce gradually as return period increases. Also the FORGEX algorithm has been improved to give a better fit to the data points and to ensure more gradual variation between locations.

The new DDF model has been fitted to rainfall frequency curves produced by the revised FORGEX analysis for the full range of durations and return periods. It is more complex and flexible than the FEH model, having 14 parameters. The new model implies a straight line extrapolation (on the Gumbel scale) of the rainfall frequency curve at very high return periods beyond the range of the data points, in contrast to the exponential increase inherent in the FEH DDF model when extrapolated beyond a return period of 1000 years.

The new DDF model was developed from the analysis of rainfall frequency curves centred on over 70 locations across the UK, and further work is planned to develop a new software package to allow the model to be implemented at any given site. Currently, the model can be applied by the CEH team at any point of interest whether it is a gauged site or not, provided that sufficient information is available to estimate a value for the at-site RMED value for each of the 11 key durations adopted in the study. Plans are in place to generalise the model results across the UK and to develop a new software package to provide rainfall estimates focused on any location. This will require the production of a set of updated digital maps of RMED.

\section{Return period analysis}

\section{Data}

The Environment Agency supplied hourly rainfall data for the period from $18^{\text {th }}$ to $21^{\text {st }}$ November 2009 , together with daily totals for the whole month, recorded at the Seathwaite Farm raingauge and also at a raingauge in the Honister Pass. The locations of the gauges are shown in Figure 1 and some

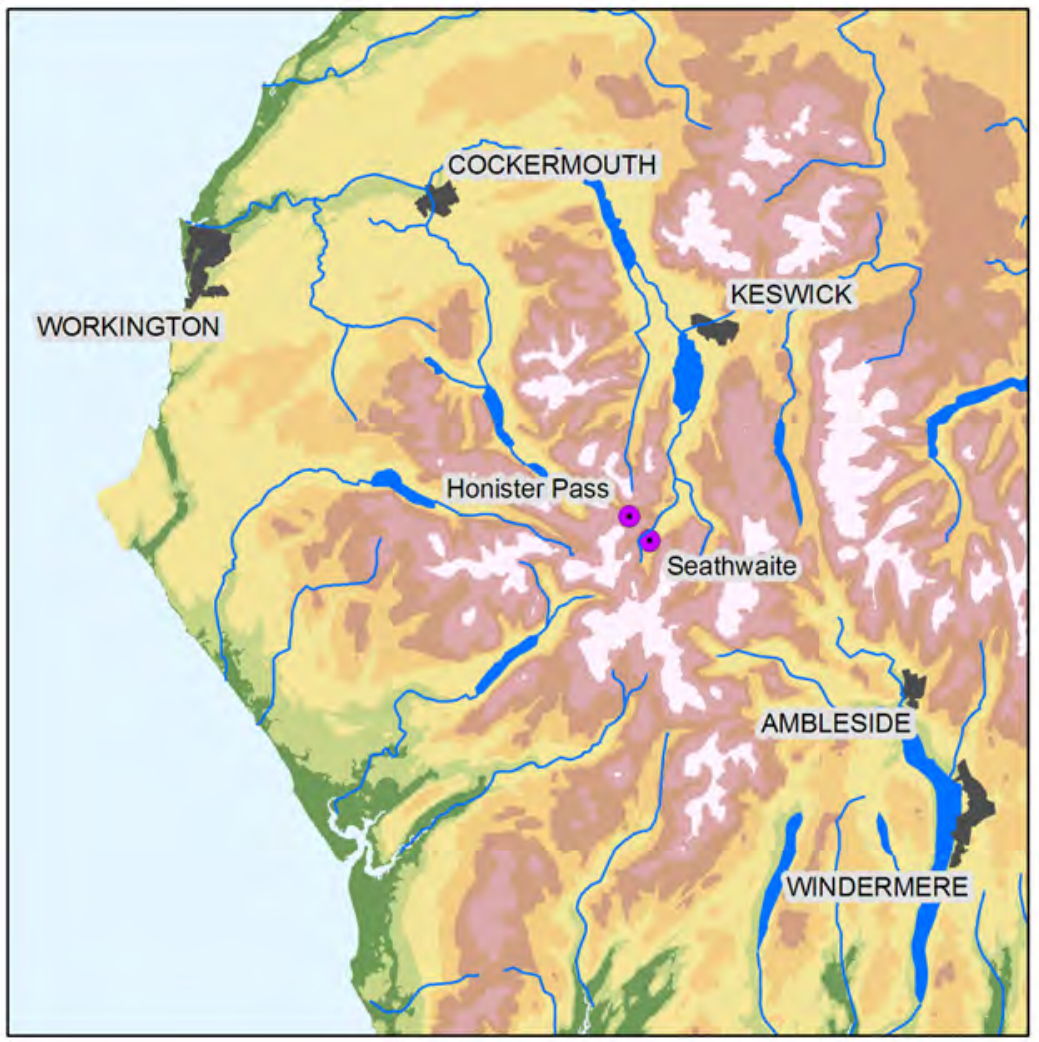

Figure 1 Map showing the locations of the two raingauge sites for which hourly data were available (c) NERC. Crown copyright 2010. all rights reserved

Table 1 Details of the raingauge sites

\begin{tabular}{llllll}
\hline Gauge & Number & Easting & Northing & $\begin{array}{l}\text { Altitude } \\
(\mathrm{m})\end{array}$ & $\begin{array}{l}\text { 1961-90 } \\
\text { SAAR } \\
(\mathrm{mm})\end{array}$ \\
\hline Seathwaite Farm & 592448 & 3235 & 5121 & 129 & 3137 \\
Honister Pass & 592463 & 3225 & 5135 & 358 & 3389 \\
\hline
\end{tabular}


information about the sites is given in Table 1.

The gauges are situated about $1.7 \mathrm{~km}$ apart in an area of very high average annual rainfall (SAAR). The Honister raingauge is located at the top of the pass connecting the Buttermere valley with the Borrowdale valley. It generally records higher rainfall depths than the Seathwaite Farm gauge, which is situated in the Borrowdale valley. However, in the case of the extreme rainfall recorded in November 2009, the maximum 24-hour value recorded at Seathwaite Farm (316.4 mm) exceeded that recorded at Honister Pass by $15 \mathrm{~mm}$.

\section{RMED estimation}

Before the new rainfall DDF model could be applied, it was necessary to obtain estimates of RMED, the median annual maximum rainfall, for each of the 11 key durations adopted in the model development. For the Honister Pass raingauge, these values had already been computed from the data available at the site, comprising daily records from 1970 to 2004 (with 15 incomplete years) and hourly records from 1982 to 2004 (with 11 incomplete years) (2004 was the last year available when the dataset was assembled at the outset of the project). The Defra study had already identified substantial differences between the RMED values derived from the updated annual maximum dataset and the 2-year return period estimates resulting from the FEH DDF at the same site.

These differences could be attributed to two factors. Firstly, it had not been possible to include hourly annual maxima from the Honister Pass raingauge in the FEH analysis because its record length was insufficient at that time. This meant that the basic data used in the mapping of the RMED variable, particularly for shorter durations, had been inadequate in this locality. Secondly, the implementation of the FEH model on the FEH CD-ROM (Centre for Ecology and Hydrology, 2009) provides rainfall frequency estimates at any point on a $1-\mathrm{km}$ grid of the UK, assuming that the nearest grid point will provide an adequate representation of the site of interest. However, in areas of rugged topography, such as Cumbria, there can be considerable differences in altitude between grid points, causing sizeable differences in rainfall estimates. In the case of the Honister gauge, the FEH software automatically chooses a nearby grid point at a lower altitude, resulting in lower rainfall estimates. The revised RMED

Table 2 Revised RMED values at Honister Pass raingauge

\begin{tabular}{lccc}
\hline Duration & $\begin{array}{l}\text { RMED } \\
\text { from FEH } \\
\text { DDF model }\end{array}$ & Revised RMED & $\begin{array}{l}\text { Number of } \\
\text { maxima } \\
(\mathrm{mm})\end{array}$ \\
\hline 1 hour & 13.4 & 19.0 & 12 \\
2 hours & 20.6 & 37.0 & 12 \\
4 hours & 31.4 & 62.6 & 12 \\
12 hours & 57.4 & 118.8 & 12 \\
24 hours & 81.0 & 149.8 & 12 \\
1 day & 69.8 & 120.3 & 20 \\
4 days & 138.8 & 224.6 & 20 \\
\hline
\end{tabular}

Table 3 Revised RMED values at Seathwaite Farm raingauge

\begin{tabular}{lccc}
\hline Duration & $\begin{array}{l}\text { RMED from FEH } \\
\text { DDF model }(\mathrm{mm})\end{array}$ & $\begin{array}{l}\text { Revised RMED } \\
(\mathrm{mm})\end{array}$ & $\begin{array}{l}\text { Number of } \\
\text { maxima }\end{array}$ \\
\hline 1 hour & 16.8 & 16.7 & 22 \\
2 hours & 26.9 & 28.1 & 22 \\
4 hours & 42.8 & 46.8 & 22 \\
12 hours & 83.7 & 88.6 & 22 \\
24 hours & 126.8 & 116.3 & 22 \\
1 day & 109.3 & 105.1 & 17 \\
4 days & 244.7 & 203.6 & 18 \\
\hline
\end{tabular}

estimates from gauge data are shown in Table 2 along with the corresponding estimates from the FEH CD-ROM.

A similar exercise was undertaken at the Seathwaite Farm gauge and the results are shown in Table 3 . This time it can be seen that the discrepancies between the FEH RMED values and those estimated from gauge data are generally smaller. The altitude of the $1-\mathrm{km}$ grid point used by the FEH CD-ROM software is higher than that of the gauge itself.

\section{Revised FORGEX analysis}

A revised FORGEX analysis focused on the Honister Pass and Seathwaite Farm raingauge sites was carried out as detailed in Stewart et al. (2010) using the revised RMED values already discussed. The resulting frequency curves were then compared with those derived from the original FEH FORGEX methodology. Figure 2 gives an example comparison for a duration of 24 hours focused on Honister Pass. The FEH FORGEX curve, produced using the FEH dataset, is shown in red and the revised curve (in green) lies above it, indicating that the new method together with the updated dataset produces rainfall estimates that are higher than the FEH method for a given return period. This result is unusual and is mainly due to the improved estimation of RMED through the inclusion of data at the raingauge site.

Figure 3 shows a comparison between the FEH FORGEX and revised FORGEX curves for the 24-hour duration focused on Seathwaite Farm. The revised curve (shown in green) lies to the right of the FEH FORGEX curve, indicating that the revised method produces lower rainfall estimates than the FEH method for a given return period. This result is typical of the sites tested throughout England, Wales and Northern Ireland (Stewart et al., 2010).

\section{Extreme event analysis}

Following the revised FORGEX analysis at the two raingauge sites, the new DDF model was fitted to allow the assessment of the return period of the rainfall depths observed during the November 2009 event. Maximum rainfall depths for durations from 1 hour to 4 days were abstracted from the hourly and daily rainfall data over the period from $18^{\text {th }}$ to $21^{\text {st }}$ November 2009. The results for the two gauge sites are shown in Tables

\section{Table 4 Comparison of return period estimates for the November 2009} event at Honister Pass

\begin{tabular}{lccc}
\hline $\begin{array}{l}\text { Duration } \\
(h)\end{array}$ & $\begin{array}{l}\text { Rainfall } \\
(\mathrm{mm})\end{array}$ & $\begin{array}{l}\text { Return period estimate (years) } \\
\text { FEH DDF } \\
\text { model }\end{array}$ & $\begin{array}{l}\text { New DDF } \\
\text { model }\end{array}$ \\
\hline 6 & 82.2 & 36 & 3 \\
12 & 157.6 & 172 & 12 \\
24 & 301.4 & 1234 & 396 \\
36 & 376.6 & 1977 & 1013 \\
48 & 391.0 & 1449 & 795 \\
72 (3 days) & 454.4 & 3240 & 1659 \\
96 (4 days) & 489.8 & 3552 & 1143 \\
\hline
\end{tabular}

Table 5 Comparison of return period estimates for the November 2009 event at Seathwaite Farm

\begin{tabular}{lllr}
\hline $\begin{array}{l}\text { Duration } \\
(h)\end{array}$ & $\begin{array}{l}\text { Rainfall } \\
(\mathrm{mm})\end{array}$ & $\begin{array}{l}\text { Return period estimate (years) } \\
\text { FEH DDF } \\
\text { model }\end{array}$ & $\begin{array}{l}\text { New DDF } \\
\text { model }\end{array}$ \\
\hline 6 & 102.4 & 22 & 51 \\
12 & 189.2 & 70 & 332 \\
24 & 316.4 & 158 & 1862 \\
36 & 392.6 & 172 & 3656 \\
48 & 405.0 & 93 & 1973 \\
72 (3 days) & 456.4 & 132 & 3380 \\
96 (4 days) & 495.0 & 109 & 2984 \\
\hline
\end{tabular}



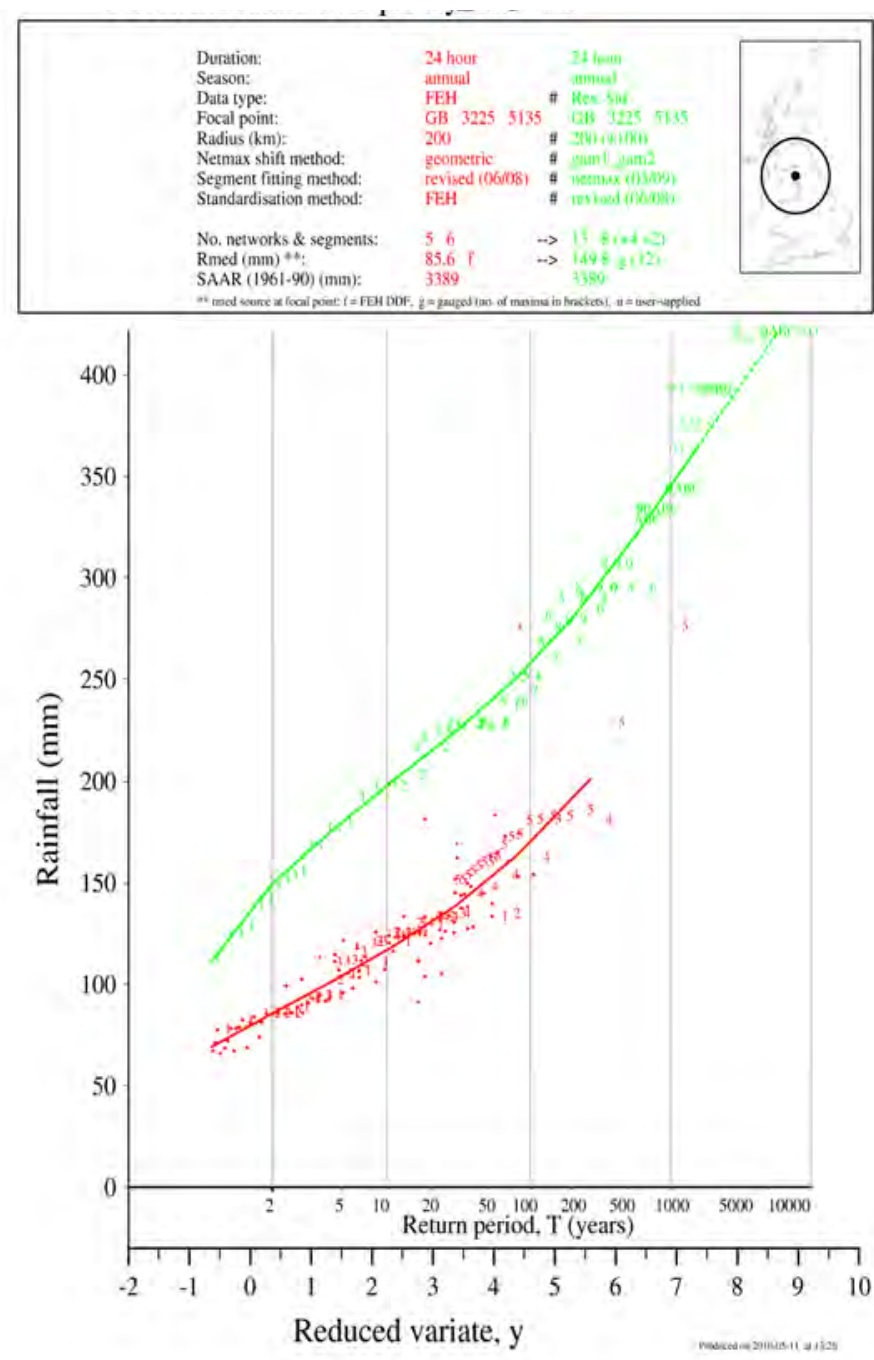

Figure 2 Comparison of the FEH FORGEX and revised FORGEX methods for the 24-hour duration focused on the Honister Pass raingauge site

4 and 5 and compared with estimates produced by the DDF model software on the FEH CD-ROM. Table 4 shows that, at Honister Pass, the return periods estimated by the new DDF model are substantially lower than those produced by the FEH model at all durations. This result is unusual when compared with other locations in the UK (see Stewart et al., 2010), and is largely due to the FEH model's underestimation of the RMED variable at the Honister Pass site. Table 5 shows comparative return periods from the two models for the Seathwaite Farm site, and here the estimated return periods from the new model exceed those from the FEH model for all the durations studied. This result is in line with other locations in the UK. At Seathwaite Farm, the duration with the highest return period was 37 hours (401.6 mm, 4202 years).

\section{Conclusions}

The results of the analysis demonstrate the value of the extended dataset in improving the estimation of RMED (the median annual maximum rainfall), particularly in areas of rugged terrain such as the Lake District. This causes the new model of rainfall depth-duration-frequency to assign lower return periods to a given rainfall depth at the Honister Pass raingauge site. The new model has the opposite effect at the Seathwaite Farm raingauge site, where the discrepancies in estimates of RMED are generally lower.

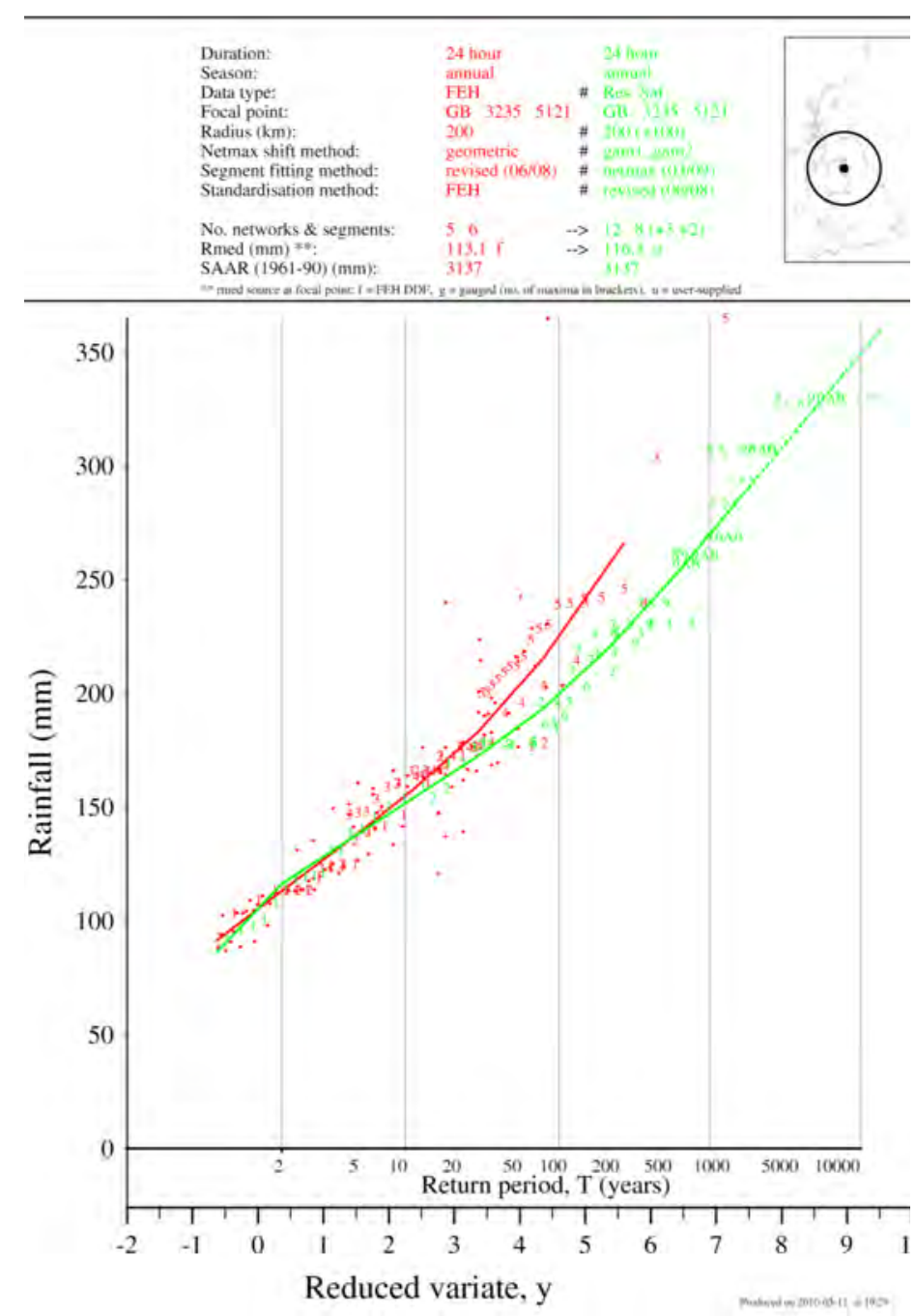

Figure 3 Comparison of the FEH FORGEX and revised FORGEX methods for the 24-hour duration focused on the Seathwaite Farm raingauge site

\section{Acknowledgements}

The development of the new rainfall DDF model was funded by Defra under the Joint Environment Agency/Defra Flood and Coastal Risk Management R\&D Programme (contract WS 194/2/39). Data for the analysis described in this paper were supplied by the Environment Agency.

\section{References}

Centre for Ecology and Hydrology 2009. FEH CD-ROM 3. CEH Wallingford.

Eden, P. and Burt, S. 2010. Extreme rainfall in Cumbria, 1820 November 2009. Weather, 65, 1, 14.

Faulkner, D. S. 1999. Rainfall frequency estimation.

Volume 2 of the Flood Estimation Handbook, Institute of Hydrology, Wallingford.

Institute of Hydrology 1999. Flood Estimation Handbook (five volumes). Institute of Hydrology, Wallingford.

MacDonald, D. E. and Scott, C. W. 2001. FEH vs FSR rainfall estimates: an explanation for the discrepancies identified for very rare events. Dams and Reservoirs, 11, 2, 28-31.

Met Office 2009. Floods in Cumbria - November 2009. http://www.metoffice.gov.uk/climate/uk/interesting/ nov2009/ 
Pedgley, D. E. 2010. The British Rainfall Organization, 19591919. Weather, 65, 5, 115-117.

Stewart, E. J., Jones, D. A., Svensson, C., Morris, D. G., Dempsey, P., Dent, J. E., Collier, C. G. and Anderson, C. W. 2010. Reservoir Safety - Long return period rainfall (two volumes). R\&D Technical Report WS 194/2/39/TR, Joint Defra/EA Flood and Coastal Erosion Risk Management RandD Programme. 